(c) (1) $\circledast$

Creative Commons Attribution -

NonCommercial 4.0 International License
Izvorni znanstveni rad

https://doi.org/10.31784/zvr.8.1.13

Datum primitka rada: 2. 12. 2019.

Datum prihvaćanja rada: 24. 1.2020.

\title{
KULTUROLOŠKI ASPEKTI POSLOVNOG PREGOVARANJA MENADŽERA HRVATSKIH PODUZEĆA
}

\author{
Marija Martinović
}

Dr. sc., izvanredan profesor, Sveučilište u Dubrovniku, Odjel za ekonomiju i poslovnu ekonomiju, Lapadska obala 7, 20000 Dubrovnik, Hrvatska; e-mail: marija.martinovic@unidu.hr

\section{Katija Vojvodić}

Dr. sc., izvanredan profesor, Sveučilište u Dubrovniku, Odjel za ekonomiju i poslovnu ekonomiju, Lapadska obala 7, 20000 Dubrovnik, Hrvatska; e-mail: katija.vojvodic@unidu.hr

\section{Ana Pušić}

Mag. oec., asistent, Sveučilište u Dubrovniku, Odjel za ekonomiju i poslovnu ekonomiju, Lapadska obala 7, 20000 Dubrovnik, Hrvatska; e-mail: apusic@unidu.hr

\section{SAŽETAK}

U kontekstu poslovnog pregovaranja od presudne je važnosti razumijevanje razlika među kulturama i njihovog utjecaja na pregovarački proces $i$ ishode pregovaranja. Štoviše, kulturološka osviještenost omogućuje pregovaračima anticipiranje i tumačenje ponašanja suprotne pregovaračke strane te olakšava postizanje željenih ciljeva i unapređuje rezultate pregovaranja. Cilj je ovoga rada bio istražiti utjecaj odabranih obilježja hrvatskih pregovarača (dob, pozicija u poduzeću i učestalost pregovaranja) na kulturološke aspekte pregovaranja (tituliranje, neverbalnu komunikaciju i iskazivanje emocija). Istraživanje je provedeno na uzorku od 256 poduzeća u Republici Hrvatskoj. Rezultati istraživanja ukazali su na postojanje pozitivne korelacije između sljedećih varijabli: iskazivanje emocija i učestalost pregovaranja, dob i tituliranje te učestalost pregovaranja i neverbalna komunikacija. Multilinearna hijerarhijska regresija dala je detaljniji uvid u odnos među varijablama. Beta koeficijent ukazao je na statistički značajnu ovisnost iskazivanja emocija i neverbalne komunikacije o prediktoru učestalost pregovaranja te tituliranja o prediktoru dob. Rad pruža uvid u hrvatsku pregovaračku praksu i može poslužiti kao polazište za provođenje budućih empirijskih istraživanja.

Ključne riječi: poslovno pregovaranje, hrvatski menadžeri, kulturološki aspekti 


\section{UVOD}

Pregovaranje se, općenito, može promatrati kao proces davanja i uzimanja, tj. razmjena informacija i ustupaka na koju su pregovaračke strane spremne pristati. U suvremenim uvjetima poslovanja, pregovaranje predstavlja dinamičan proces tijekom kojeg se istodobno upravlja njegovim integralnim, ali nerijetko različitim dimenzijama (Age, Eklinder-Frick, 2017). Taj dinamični proces ujedno pretpostavlja i sustavno upravljanje odnosima unutar kojih se odvija pregovaranje (Lewthwaite, 2006). Osim što se smatra jednom od najvažnijih vještina suvremenih menadžera, uz pregovaranje se, osim znanosti, često vezuje i riječ umjetnost. Time se povezuje i prožima međudjelovanje pregovaračkih strana na koje utječu dimenzije poput kulture, stalno mijenjajućih okolnosti, očekivanja i sposobnosti (Gates, 2012). Iz tih je razloga razvidno kako pregovarački proces zahtijeva prilagodbu i predanost pregovarača (Oliver, 2011), ali i njegovu odgovornost (Lempereur, 2012). Navedena obilježja utječu na razvijanje pregovaračkih vještina te ih čine iznimno zahtjevnim, složenim i izazovnim zadatkom. Ne iznenađuje, stoga, što se iskusni i vješti pregovarači smatraju važnom imovinom koja pridonosi financijskim rezultatima poduzeća (ElShenawy, 2010).

Autori Uher i Loosemore (2004) poslovno pregovaranje poistovjećuju s „igrom strategija“. Strateško planiranje u procesu pregovaranja uvelike olakšava donošenje taktičkih odluka koje vode postizanju konačnog cilja (Frascogna, Hetherington, 2001), a uporaba unaprijed određenih strategija i taktika povećava vjerojatnost uspješnog ishoda cjelokupnog pregovaračkog procesa (Hoechlin, 2018). Dinamičnost pregovaračkog procesa podrazumijeva i kontinuiranu prilagodbu, tj. uvođenje različitih strategija u pregovarački proces (Olekalns, Weingart, 2008). Izmjena strategija tijekom pregovaranja, uvođenje novih ili odustajanje od već primijenjenih strategija mogu pridonijeti anticipiranju poteza suprotne strane, ali i učinkovitijem odgovoru na zahtjeve suprotne strane. Međutim, specifičnost i jedinstvenost svakog pregovaračkog procesa ujedno ograničava definiranje strategija koje bi se mogle okarakterizirati kao zajedničke ili opće za svaki takav proces. Štoviše, Korobkin (2014) naglašava da je pregovaranje aktivnost koja je previše ovisna o kontekstu što uvjetuje nepostojanje skupa taktika koje bi mogle biti univerzalno učinkovite.

lako se posljednjih pedesetak godina velika pozornost posvećuje pregovaranju, posebice u kontekstu organizacijskog ponašanja i znanosti o menadžmentu (Brett, Thompson, 2016), u suvremenom, turbulentnom i stalno mijenjajućem poslovnom okruženju sve se veći naglasak stavlja na dimenzije koje su njegov sastavni dio. One se ponajprije odnose na rizik, neizvjesnost, promjene, konflikte, psihološke procese i kulturološku osviještenost te na ulogu informacijskokomunikacijskih tehnologija u cjelokupnom procesu. Stoga, Saorin-lborra, Redondo-Cano, Revuelto-Taboada (2013) ističu kako je upravo razumijevanje utjecaja pregovaračkog konteksta na ponašanje pregovarača presudno za predviđanje reakcija i poteza suprotne strane te postizanje najpovoljnijeg sporazuma. Uravnoteženost razmišljanja pregovarača i usredotočenost na razumijevanje interesa i prioriteta suprotne pregovaračke strane važne su pregovaračke vrline koje mogu pridonijeti pozitivnom pregovaračkom ozračju i konačnom ishodu pregovaranja. U tom smislu, Gates (2012) tvrdi da je učenje o pregovaranju ujedno i vrsta vježbe samosvijesti koja pregovaračima omogućuje da se izbore s pritiscima, dvojbama i stresom tijekom pregovaračkog procesa. 
Cilj je ovoga rada istražiti utjecaj odabranih obilježja hrvatskih pregovarača na stil pregovaranja koji proizlazi iz organizacijske kulture njihovih poduzeća. Polazna pretpostavka je da odabrana obilježja pregovarača (dob, pozicija u poduzeću te učestalost pregovaranja) imaju utjecaj na kulturološku stranu pregovaračkog procesa. U okviru „meke“ strane pregovaranja istražuju se tri varijable iskazivanje emocija, tituliranje te neverbalna komunikacija. Nakon uvodnog dijela, u drugom se dijelu daje pregled literature vezan za odabrane kulturološke aspekte poslovnog pregovaranja kao i pregled dosadašnjih istraživanja poslovnog pregovaranja u Republici Hrvatskoj. U trećem dijelu predstavljena je metodologija istraživanja, dok se u četvrtom dijelu razmatraju rezultati istraživanja. Konačno, rad je zaokružen zaključnim razmatranjima u kojima su istaknuta ograničenja istraživanja kao i preporuke za daljnja istraživanja i produbljivanja ove tematike.

\section{PREGLED LITERATURE}

\section{1 Utjecaj kulturoloških obilježja na pregovarački proces}

Utjecaj kulture na poslovno pregovaranje moguće je promatrati iz perspektive različitih klasifikacija. Suvremeno poslovanje i pregovaranje u globalnom okruženju zahtijevaju od pregovarača dublje razumijevanje kulturoloških razlika i načina na koji se te razlike odražavaju na interese i primijenjene strategije u pregovaračkom procesu (Brett, 2017). Osim toga, Sobral, Carvalhal, Almeida (2008) ističu da uspješni međukulturalni pregovori zahtijevaju i razumijevanje pregovaračkog stila druge strane te prihvaćanje i poštivanje njezinih kulturnih uvjerenja i normi. Slično tome, Brett i Mitchell (2019) naglašavaju kulturološku osviještenost pregovarača u kontekstu razumijevanja i poštivanja ponašanja druge pregovaračke strane. Različite kulturološke dimenzije mogu izravno utjecati na ishode pregovaranja (Thomas, 2008), ali i na mnoge aspekte pregovaračevih pretpostavki i strategija koje koristi tijekom pregovaranja (Gunia, Brett, Gelfand, 2016).

S tim u vezi, Acuff (2008) ističe četiri kulturološka činitelja koja utječu na pregovaranje među različitim kulturama, a odnose se na percepciju vremena, individualizam/kolektivizam, uređenost uloga i obrasce komunikacije. S obzirom na vremensku dimenziju, Carnevale (2019) naglašava da vrijeme može utjecati na mnoge aspekte pregovaranja, od osnovnih pregovaračkih procesa i ishoda, odabira taktika, emocionalnih procesa, spoznaje i motivacije. Nadalje, Salacuse (1998) identificira deset kulturoloških razlika u procesu pregovaranja koje se odnose na cilj pregovaranja, pregovarački stav, osobni stil pregovarača, komunikaciju, vremensku dimenziju pregovaranja, emocije u pregovaranju, oblik ugovora, usuglašavanje oko elemenata ugovora, organizaciju pregovaračke skupine i preuzimanje rizika. lako su brojne kulturološke dimenzije koje mogu utjecati na pregovarački proces, u nastavku se daje osvrt na osobni stil pregovarača, neverbalnu komunikaciju i ulogu emocionalnih stanja u kontekstu pregovaranja.

Svaki pregovarač ima svoj osobni stil koji je pod izravnim utjecajem kulture iz koje pregovarač dolazi te postaje sastavni dijelom pregovaračkog procesa. Osobni stilovi pregovarača izravno utječu na način njegova komuniciranja, pregovarački proces i ishode pregovaranja (Wang, 2018), ali i na rješavanje konflikata (Dwyer, Hopwood, 2019). Osobni stil pregovarača može biti formalan i neformalan. Kad se govori o formalnom stilu do izražaja dolazi formalnost s obzirom na način komunikacije, tj. korištenje pripadajuće titule u međusobnom obraćanju (npr. gospodine, doktore, 
profesore, i sl.), izbjegavanje razgovora o privatnom ili obiteljskom životu sugovornika i inzistiranje na poslovnim temama. Njemački pregovarači tipičan su primjer formalnog stila. $S$ druge strane, američki pregovarači imaju neformalan osobni stil uz koji se vezuje ležerniji stil odijevanja, komunikacija sa sugovornikom u kojoj se ne koristi tituliranje, nego se osobu oslovljava imenom te se nastoji brzo razviti prijateljski odnos sa suprotnom pregovaračkom stranom. Ukratko, neformalni pregovarači nastoje stvoriti ležerno i ugodno okruženje (Khan, Ebner, 2019).

Općeprihvaćena je tvrdnja da je razumijevanje neverbalne komunikacije od ključne važnosti za međukulturalne pregovore. Uz verbalnu komunikaciju, i neverbalna komunikacija utječe na primatelja poruke. Pojednostavljeno rečeno, neverbalna komunikacija odnosi se na komuniciranje bez uporabe riječi. Drugim riječima, pod neverbalnom komunikacijom podrazumijeva se sve što sudjeluje u razgovoru, a nije govor (Tomašević Lišanin, Kadić-Maglajlić, Drašković, 2019). Prema Hendon, Hendon, Herbig (1996), neverbalno ponašanje je svaki oblik namjernog ili nenamjernog ponašanja koji primatelj poruke interpretira određenim značenjem. Neverbalno ponašanje ima različita značenja za ljude koji pripadaju različitim kulturama i nerijetko je glavni razlog nerazumijevanja i sukoba. Neverbalna komunikacija uključuje izraz lica, kontakt očima, geste, pokrete tijela, držanje, fizički izgled i dodir. Često se naziva i „tihim jezikom“ koji se formalno ne uči, ali koji je postojao i prije nego je jezik nastao (Calero, 2005).

Poseban je oprez potreban pri tumačenju i razumijevanju neverbalnih znakova koje je potrebno razmatrati uširem kontekstu, uzimajući u obzir verbalni sadržaj i njegovo okruženje. U kroskulturnoj komunikaciji pregovarači moraju posebnu pozornost posvetiti neverbalnim znakovima kako bi bili primjereni kulturi s kojom se pregovara (Hurn, Tomalin, 2013). U kontekstu neverbalne komunikacije emocija, Tracy, Randles, Steckler (2015) ističu da izražavanje emocija igraju ključnu ulogu u vođenju društvene interakcije i ponašanja. Također, naglašavaju da je izražavanje emocija oblik prilagodljivog komunikacijskog signala koji ima veliki utjecaj na svakodnevnu društvenu komunikaciju.

Bitno je razumjeti ulogu emocionalnih stanja u kontekstu pregovaranja i njihovog utjecaja na tijek pregovaračkog procesa. Tako Barry, Fulmer, Goates (2006) ističu da pozitivni osjećaji povećavaju očekivanja, suradničku pregovaračku klimu i zajedničke koristi od pregovaranja. Pregovarači bi trebali biti svjesni svojih sposobnosti kontroliranja emocija tijekom pregovaranja. Općenito, kontroliranje emocija omogućuje pregovaraču da in koristi kao svoju prednost (Carrell, Heavrin, 2004). Butt i Choi (2010) tvrde da jačina i priroda odnosa između emocija i ponašanja pregovarača ovise o snazi pregovarača. Osim toga, mnogi pregovarači strahuju da će pregovori u jednom trenutku postati emocionalni i, slijedom toga, previše osobni (Pinkley, Northcraft, 2014). Treba istaknuti da dinamičan tijek pregovora koji ne prate očekivani rezultati može uvelike utjecati na emocionalna stanja pregovaračkih strana i poteze na koje se odlučuju pod takvim utjecajem.

Poznato je da kako emocionalni intenzitet raste, ljudi postaju skloniji donositi neracionalne, emocionalno uvjetovane odluke (Warner, 2011). S tim u vezi, autori Jäger, Loschelder, Friese (2015) navode samoregulaciju kao jedan od moćnih alata za savladavanje izazova s kojima se suočavaju pregovarači. Sposobnost upravljanja i kontrole nad vlastitim ponašanjem i mislima te njihova prilagodba u skladu sa zahtjevima situacije daju pregovaraču prednost za pregovaračkim 
stolom. Posljedično, važnost i uspješnost upravljanja tim emocionalnim procesima prepoznaje se i odražava kroz rješavanje sukoba. Wang, Han, Su (2017) naglašavaju važnost razumijevanja utjecaja emocija na oblikovanje razvoja i rješavanja sukoba, a Posthuma (2012) posebice ukazuje na potrebu razumijevanja emocija kako bi se lakše i učinkovitije upravljalo sukobima. $S$ druge strane, nepoznavanje međukulturnih razlika u stilovima rješavanja sukoba može rezultirati frustracijom zbog ponašanja druge pregovaračke strane (Blume, 2017).

\section{2 Pregled istraživanja poslovnog pregovaranja u Republici Hrvatskoj}

Istraživanja praktičnih aspekata pregovaranja u Republici Hrvatskoj uglavnom se razvijaju u dva smjera te se pri tome oslanjaju na Hofstedeov široko rasprostranjeni model kulturalnih razlika ili se orijentiraju na pojedinačne elemente poslovnog pregovaranja u različitim kontekstima. Prva skupina istraživanja, koja se oslanja na Hofstedeov model kulturalnih razlika, uzima u obzir šest dimenzija putem kojih kultura utječe na poslovanje (udaljenost moći, izbjegavanje neizvjesnosti, individualizam/kolektivizam, muževnost/maskulinitet i ženstvenost/feminitet društva, kratkoročna/ dugoročna vremenska orijentacija te uživanje). Oslanjajući se na Hofstedeov koncept dimenzija nacionalne kulture, Lažnjak (2011) bavila se problematikom dimenzije nacionalne inovacijske kulture u Hrvatskoj. Rezultati studije inovacijske kulture pokazali su da Hrvatska ima nisku razinu inovativnosti te, posljedično, nizak stupanj dugoročne orijentacije i visok stupanj izbjegavanja nesigurnosti. Također, stupanj udaljenosti moći bio je relativno visok, dok je razina individualnosti bila niska sugerirajući prevladavajuće kolektivističke vrijednosti. Niski indeks muževnosti upućivao je na to da se Hrvatska kreće prema umjereno ženskom tipu društva.

Hofstedeov koncept dimenzija nacionalne kulture bio je temelj istraživanja kojeg su proveli Podrug, Filipović i Stančić (2014), a analizirale su se kulturne razlike između Hrvatske, Brazila, Njemačke i Srbije. Pokazalo se da se, u usporedbi s originalnim Hofstedovim istraživanjem, indeks udaljenosti moći u Hrvatskoj smanjio, dok nije bilo većeg pomaka u vidu manjeg stupnja izbjegavanja nesigurnosti. Hrvatska je pokazala tendencije transformacije u individualističko društvo, a od sve četiri promatrane zemlje Hrvatska se pokazala kao zemlja s najizraženijom kratkoročnom orijentacijom. U jednom od skorašnjih istraživanja, Rajh, Budak i Anić (2016) primijenili su Hofstedeov upitnik nacionalne kulture u Hrvatskoj i ispitivali regionalne razlike u stavovima hrvatskih građana o dimenzijama nacionalne kulture. Na temelju ankete velikog uzorka građana u Hrvatskoj, rezultati su pokazali da hrvatsku nacionalnu kulturu obilježava niža razina udaljenosti moći, umjereno viša razina individualizma, niska razina maskuliniteta i niža razina dugoročne orijentacije, što su sve obilježja razvijenih zemalja. Indeks izbjegavanja nesigurnosti pokazao se visokim, što je obilježje post-tranzicijskih zemalja.

Istraživanje kulturoloških razlika koje utječu na stilove odlučivanja proveli su Dabić, Podrug i Tipurić (2015) uspoređujući četiri države - Hrvatsku, Sloveniju, Bosnu i Hercegovinu i Mađarsku. U usporedbi s originalnim Hofstedovim istraživanjem, istaknuto je smanjenje indeksa udaljenosti moći i izbjegavanja nesigurnosti i rizika te sve izraženija individualistička orijentacija. Međutim, ističu još uvijek razvidnu dominaciju „muških“ vrijednosti u kulturi, tj. naglasak na asertivnosti, konkurentnosti, uspjehu, dostignućima i izazovima, a manje na „ženskim“ vrijednostima - suradnji, kvaliteti života i brizi za druge. U procesu odlučivanja Hrvati su vrlo oprezni, nastoje prikupiti sve 
raspoložive informacije, razmotriti različite opcije i uzeti u obzir sve moguće posljedice koje odluke mogu prouzročiti.

Istraživanje temeljeno na komparativnoj analizi stilova upravljanja konfliktima između Hrvatske i SAD-a provele su Podrug i Gauta (2013). Utvrđeno je da se u hrvatskim poduzećima konflikti rješavaju kompromisom i međusobnom prilagodbom. Argumentirajući postupnu transformaciju Hrvatske u individualističko društvo, ističu kako su kompromisno rješavanje konflikata i suradnja između zaposlenika i nadređenih bitna obilježja individualističkih društava. Međutim, navode i da se nacionalna kultura ne može primjenjivati za svakog pojedinca te da unutar individualističke kulture može biti prisutna i kolektivistička orijentacija.

Druga skupina istraživanja odnosi se uglavnom na empirijska istraživanja pojedinih elemenata poslovnog pregovaranja u različitim kontekstima. Tako su Križman Pavlovići Kalanj (2008) istraživali ulogu koja se pridaje poslovnom pregovaranju kao jednom od izvora konkurentske prednosti u hrvatskim poduzećima. Rezultati njihova istraživanja pokazali su da je u hrvatskim poduzećima uvelike prisutna svijest o tome da sposobnost poslovnog pregovaranja predstavlja značajan izvor konkurentske prednosti, ali da ta svijest nije dostatno operacionalizirana. Dvije trećine hrvatskih poduzeća izjasnilo se da je sposobnost poslovnog pregovaranja značajni izvor konkurentske prednosti, iako je samo $40 \%$ ispitanih poduzeća redovito ulagalo u razvijanje pregovaračke sposobnosti svojih zaposlenika. Nadalje, važnost pregovaranja kao sastavnog dijela prodajnog procesa razmatrali su autori Perkov, Primorac i Kozina (2016). Rezultati njihova istraživanja ukazuju na nedostatak svijesti zaposlenika o važnosti pripreme prije početka pregovora o prodaji. Osim neodgovarajuće pripreme za pregovarački proces, uočeno je i nedostatno poboljšavanje pregovaračkih vještina. S tim u vezi, Tomašević Lišanin (2004) je isticala da se edukacija o pregovaranju rijetko provodila u hrvatskim poduzećima. Razlozi koji su se često navodili odnosili su se na nedostatna financijska sredstva ili nerazumijevanje viših upravljačkih razina.

Autorice Tomašević Lišanin, Razum i Marić (2015) analizirale su vještine i pregovaračko ponašanje hrvatskih poduzetnika, a za obilježja koja određuju razinu pregovaračkih sposobnosti razmatrane su kognitivna, socijalna i emocionalna inteligencija. Cilj je bio istražiti razinu samosvijesti i samopoštovanja poduzetnika u pregovaračkim situacijama kako bi se otkrile moguće razlike u odnosu na razinu njihovih vještina. Istraživanje je pokazalo da hrvatski poduzetnici nemaju dostatno razvijenu emocionalnu i socijalnu inteligenciju u kontekstu pregovaračkog procesa, ali istodobno sebe smatraju uspješnim pregovaračima $s$ razvijenim pregovaračkim vještinama. Za razliku od američke kulture koja je vrlo neformalna s obzirom na način komunikacije, uvažavanje starijih osoba i stečenih akademskih titula, Tomašević Lišanin, Kadić-Maglajlić i Drašković (2019) ističu da je Hrvatska, poput većina europskih zemalja vrlo formalna pa se nekorištenje pripadajuće titule u međusobnom obraćanju smatra nedostatkom uvažavanja ili čak i uvredljivim.

$\mathrm{Na}$ temelju prethodno istaknutih istraživanja razvidna je nedostatna zastupljenost problematike poslovnog pregovaranja, praktičnih aspekata pregovaranja u Hrvatskoj kao i rezultata empirijskih istraživanja. Empirijski podaci o hrvatskoj poslovnoj praksi i pregovaračkom ponašanju hrvatskih poslovnih ljudi još su uvijek nedovoljno istraženi kako bi omogućili donošenje zaključaka na nacionalnoj razini. 


\section{METODOLOGIJA ISTRAŽIVANJA}

Za potrebe ovog rada provedeno je anketno istraživanje na uzorku menadžera hrvatskih poduzeća od ožujka do lipnja 2017. Baza za odabir poduzeća bio je registar poduzeća Hrvatske gospodarske komore. Ankete su slane ispitanicima elektroničkom poštom. Prije provođenja glavnog istraživanja, provedeno je preliminarno istraživanje kako bi se utvrdila pravilna strukturiranost upitnika. Cilj je rada bio ispitati utjecaj obilježja menadžera kao pregovarača na kulturološke aspekte komuniciranja (slika 1), a anketa je kreirana temeljem pregleda relevantne literature (Hendon, Hendon, Herbig, 1996; Salacuse, 1998; Katz, 2006; Kopelman, Rosette, Thompson, 2006; Katz, 2008; Kopelman, Rosette, 2008). Predloženi model sastoji se od ukupno šest varijabli. Varijable dob, radna pozicija i učestalost pregovaranja predstavljaju obilježja pregovarača, dok se kulturološki aspekti analiziraju kroz varijable iskazivanje emocija, tituliranje i neverbalna komunikacija.

Slika 1. Predloženi model

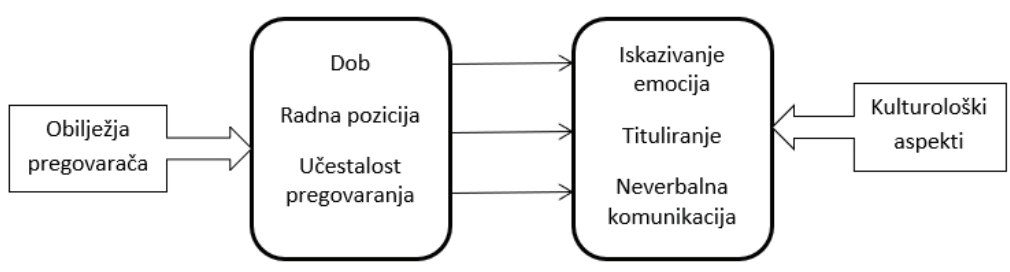

Izvor: autori

U tablici 1 prikazane su promatrane varijable s pripadajućim načinom mjerenja. Mjerne skale kreirane su na temelju rezultata i sugestija iz preliminarnog istraživanja. Prve tri varijable su zavisne. Iskazivanje emocija mjerilo se stupnjem suzdržanosti od iskazivanja emocija u rasponu od „u potpunosti suzdržan“ do „u potpunosti iskazujem emocije“. Varijabla tituliranje mjerila se iskazivanjem stava menadžera koliko im je važno oslovljavanje sugovornika njegovim punim naslovom u rasponu od „potpuno nevažno“ do „vrlo važno“. Za varijablu neverbalna komunikacija tražilo se od ispitanika da usporede važnost neverbalne i verbalne komunikacije. Raspon odgovora bio je od „potpuno nevažna“ do vrlo važna“. Sljedeće tri varijable - dob, radna pozicija i učestalost pregovaranja su nezavisne varijable, odnosno prediktori. Varijabla dob odnosi se na godine starosti ispitanika podijeljene u pet razreda. Druga nezavisna varijabla je radna pozicija gdje su se ispitanici trebali opredijeliti za jedan od dva položaja na hijerarhijskoj ljestvici u svom poduzeću: srednja i najviša razina menadžmenta. Naposljetku, varijabla učestalost pregovaranja ukazuje na iskustvo pregovarača, odnosno pokazuju je li pregovaranje rutinska ili tek sporedna aktivnost. Za to su pitanje ispitanici mogli birati između tri odgovora: nikad ili rijetko, ponekad i redovito. 
Tablica 1. Pregled varijabli

\begin{tabular}{|c|c|}
\hline Varijable & Mjere \\
\hline Iskazivanje emocija & U potpunosti suzdržan \\
& Umjereno suzdržan \\
& Suzdržan samo u početku pregovora \\
U potpunosti iskazujem emocije
\end{tabular}

Izvor: autori

Analiza podataka dobivenih anketnim istraživanjem provela se u tri koraka. U prvom koraku izložili su se osnovni podaci o uzorku, deskriptivna statistika, test normalnosti distribucije te karakteristike uzorka (frekvencije). $U$ drugom koraku ispitalo se postojanje statistički značajne povezanosti između zavisnih i nezavisnih varijabli. Naposljetku, u trećem koraku primijenila se metoda multilinearne hijerarhijske regresije kako bi se ispitao pojedinačni doprinos svakog prediktora u objašnjavanju varijance zavisnih varijabli. Ukupno je poslano 1110 anketnih upitnika, a vraćeno ih je 256 valjano popunjenih, što čini stopu povrata od $23 \%$.

\section{REZULTATI ISTRAŽIVANJA}

Rezultati dobiveni istraživanjem obrađeni su koristeći statistički program SPSS 20.0. Tablica 2 prikazuje deskriptivnu statistiku promatranih varijabli uključujući aritmetičku sredinu, standardnu devijaciju te koeficijente asimetrije i zaobljenosti. 
Tablica 2. Deskriptivna statistika

\begin{tabular}{|c|c|c|c|c|}
\hline Varijable & $\begin{array}{c}\text { Aritmetička } \\
\text { sredina }\end{array}$ & $\begin{array}{c}\text { Standardna } \\
\text { devijacija }\end{array}$ & $\begin{array}{c}\text { Koeficijent } \\
\text { asimetrije }\end{array}$ & $\begin{array}{c}\text { Koeficijent } \\
\text { zaobljenosti }\end{array}$ \\
\hline Iskazivanje emocija & 2,285 & 0,8904 & 0,213 & $-0,690$ \\
\hline Tituliranje & 2,637 & 1,0004 & $-0,334$ & $-0,937$ \\
\hline Neverbalna komunikacija & 2,035 & 0,5265 & 0,042 & 0,636 \\
\hline Dob & 1,637 & 0,4819 & $-0,572$ & $-1,686$ \\
\hline Radna pozicija & 2,613 & 0,5556 & $-1,080$ & 0,172 \\
\hline Učestalost pregovaranja & 2,285 & 0,8904 & 0,213 & $-0,690$ \\
\hline
\end{tabular}

Izvor: izračun autora

Koeficijenti asimetrije i zaobljenosti ukazuju na stupanj normalnosti distribucije promatranih varijabli. Uvriježene granice tolerancije za koeficijent asimetričnosti su od -1 do 1, a za koeficijent zaobljenosti od -2 do 2 (Hair et al., 2016: 54). Može se zaključiti da se sve varijable nalaze u prihvatljivim granicama simetrije i zaobljenosti.

Frekvencije varijabli prikazane su u tablici 3. Najveći dio ispitanih menadžera umjereno je suzdržan u iskazivanju emocija prilikom poslovnog pregovaranja (41\%), a skoro $30 \%$ njih suzdržano je tek na početku pregovaranja. Preostalih $30 \%$ nalazi se u krajnostima. Petina je potpuno suzdržana od pokazivanja bilo kakvih emocija, a tek malo više od $9 \%$ menadžera priznaje da uopće ne skriva emocije prilikom poslovnog pregovaranja. 
Tablica 3. Frekvencije odabranog uzorka menadžera

\begin{tabular}{|l|c|c|}
\hline \multicolumn{1}{|c|}{ Varijable } & Frekvencija & Udjel (\%) \\
\hline Iskazivanje emocija & 51 & 19,9 \\
U potpunosti suzdržan & 105 & 41,0 \\
Umjereno suzdržan & 76 & 29,7 \\
Suzdržan samo u početku pregovora & 24 & 9,4 \\
U potpunosti iskazujem emocije & 47 & 18,4 \\
\hline Tituliranje & 50 & 19,5 \\
Potpuno nevažno & 108 & 42,2 \\
Djelomično nevažno & 51 & 19,9 \\
Djelomično važno & 31 & 12,1 \\
Vrlo važno & 185 & 72,3 \\
\hline Neverbalna komunikacija & 40 & 15,6 \\
Potpuno nevažna & & \\
Jednako važna kao verbalna & 70 & 27,3 \\
Vrlo važna & 82 & 32,0 \\
\hline Dob & 64 & 25,0 \\
25-34 & 36 & 14,1 \\
35-44 & 4 & 1,6 \\
\hline 45-54 & & \\
55-64 & 93 & 36,3 \\
65 i više & 163 & 63,7 \\
\hline Radna pozicija & 91 & 31,6 \\
Menadžer srednje razine & 166 & 64,8 \\
Menadžer najviše razine & & \\
\hline Učestalost pregovaranja & & \\
Nikada/rijetko & & \\
Ponekad & & \\
Redovito & & \\
\hline
\end{tabular}

Izvor: izračun autora

Tituliranje sugovornika je tek djelomično važno za većinu ispitanika ( $42 \%)$. Ostali ispitanici su se gotovo podjednako rasporedili na ostale ponuđene odgovore (18,4 - 19,9\%). Najviše iznenađuje podatak da je razumijevanje i tumačenje govora tijela sugovornika prioritet za samo 15,6 \% ispitanika posebice zato što u uzorku prevladavaju menadžeri najviše razine $(63,7 \%)$ i menadžeri koji redovito pregovaraju (64,8\%). Detaljnijom analizom utvrdilo se da od ukupno 256 menadžera njih 113, odnosno $44 \%$ pripada najvišoj razini i redovito pregovara, stoga je rezultat $15,6 \%$ niži od očekivanog. Ipak, za većinu je menadžera $(72,3 \%)$ neverbalna komunikacija jednako važna kao i verbalna. Menadžeri u ovom uzorku pripadaju mladim dobnim skupinama s obzirom na to da ih je 
gotovo polovica mlađa od 45 godina. Tablica 4 daje odgovor na pitanje postoji li statistički značajna povezanost između zavisnih i nezavisnih varijabli.

Tablica 4. Koeficijenti korelacije

\begin{tabular}{|c|c|c|c|}
\hline & Iskazivanje emocija & Tituliranje & $\begin{array}{c}\text { Neverbalna } \\
\text { komunikacija }\end{array}$ \\
\hline Dob & 0,049 & $0,282^{*}$ & $-0,089$ \\
\hline Radna pozicija & $-0,159^{*}$ & $-0,080$ & $-0,011$ \\
\hline Učestalost pregovaranja & $0,229^{*}$ & 0,028 & $0,206^{*}$ \\
\hline${ }^{*} p<0,05$.
\end{tabular}

Izvor: izračun autora

Vrijednosti koeficijenata korelacije ukazuju na statistički značajnu povezanost među nekim prikazanim varijablama. Rezultati statističke obrade podataka potvrđuju da menadžeri najviše razine nastoje prikriti emocije tijekom poslovnog pregovaranja. $S$ druge strane, menadžeri nižih razina slobodniji su $\mathrm{u}$ iskazivanju emocija. Učestalost pregovaranja pozitivno je povezana $\mathrm{s}$ iskazivanjem emocija. To posebice vrijedi u slučaju kada se redovito pregovara s istim osobama jer su tada pregovarači opušteniji i skloniji iskazivanju osjećaja. Također, razvidna je pozitivna korelacija između varijabli dob i tituliranje. Slijedom toga, može se zaključiti kako stariji menadžeri više drže do formalnosti u ophođenju s poslovnim partnerima. Nasuprot tome, mlađi se pregovarači brže okreću manje formalnom obliku komunikacije. Naposljetku, utvrđena je pozitivna veza između varijabli učestalost pregovaranja i neverbalne komunikacije. To je i sasvim logično jer se tumačenje znakova tijela može smatrati vještinom koja se razvija s iskustvom. Pregovarač početnik zasigurno će svu pažnju usmjeriti na verbalnu komunikaciju. Tek kad verbalna komunikacija postane rutinska, može početi pridavati pozornost neverbalnim oblicima komunikacije.

Sljedeća faza u analizi podataka bila je utvrđivanje koliko varijance zavisne varijable objašnjava pojedina nezavisna varijabla. $U$ tu je svrhu izrađena multilinearna hijerarhijska regresija za svaku zavisnu varijablu (tablica 5). To je vrsta linearne regresije gdje se u model postupno uvodi jedan po jedan prediktor kako bi se utvrdio specifičan doprinos svakog prediktora $\left(\Delta R^{2}\right)$ na objašnjenje varijance zavisne varijable. Najprije je u regresijsku analizu uvršten prediktor dob (model 1), zatim radna pozicija (model 2) i na kraju učestalost pregovaranja (model 3). 
M. Martinović, K. Vojvodić, A. Pušić: Kulturološki aspekti poslovnog pregovaranja menadžera hrvatskih... Zbornik Veleučilišta u Rijeci, Vol. 8 (2020), No. 1, pp. 103-119

Tablica 5. Rezultati multilinearne hijerarhijske regresije

\begin{tabular}{|c|c|c|c|}
\hline Zavisne varijable & Model 1 & Model 2 & Model 3 \\
\hline Iskazivanje emocija & & & \\
\hline $\mathrm{R}^{2}$ & 0,002 & 0,006 & 0,024 \\
\hline$\Delta \mathrm{R}^{2}$ & 0,002 & 0,004 & 0,018 \\
\hline$\Delta \mathrm{F}$ & 0,600 & 1,019 & 4,554 \\
\hline Sig. & 0,439 & 0,314 & 0,034 \\
\hline & & & \\
\hline $\mathrm{R}^{2}$ & 0,027 & 0,034 & 0,035 \\
\hline$\Delta \mathrm{R}^{2}$ & 0,027 & 0,007 & 0,001 \\
\hline$\Delta \mathrm{F}$ & 1,722 & 1,913 & 0,211 \\
\hline Sig. & 0,041 & 0,168 & 0,646 \\
\hline$\Delta \mathrm{R}^{2}$ & & & \\
\hline$\Delta \mathrm{F}$ & 0,008 & 0,010 & 0,026 \\
\hline Sig. & 0,008 & 0,002 & 0,016 \\
\hline Neverbalna komikanje & 0,026 & 0,005 & 0,107 \\
\hline & 0,056 & 0,045 & 0,004 \\
\hline
\end{tabular}

Izvor: izračun autora

Kao što je razvidno iz tablice 5 , sva tri prediktora zajedno objašnjavaju 2,4 \% varijance iskazivanja emocija. Gledajući pojedinačni doprinos, prediktor dob objašnjava $0,2 \%$, radna pozicija $0,4 \%$, a učestalost pregovaranja objašnjava najviše varijance i to sa 1,8 \%. Regresijskom analizom za varijablu tituliranje utvrđen je zajednički doprinos objašnjenju varijance od 3,5 \%. Ipak, najveći pojedinačni doprinos ima varijabla dob i to $2,7 \%$, dok dosta skromniji doprinos imaju varijable radna pozicija $(0,7 \%)$ i učestalost pregovaranja (0,1\%). Neverbalna komunikacija je ovim regresijskim modelom objašnjena s 2,6 \% varijance. Najveći udio u varijanci ima prediktor učestalost pregovaranja (1,6\%), dok je udio prediktora dob $0,8 \%$, a prediktora radna pozicija $0,2 \%$.

U tablici 6 prikazani su beta koeficijenti regresijskih modela, koji odražavaju jačinu ovisnosti zavisne varijable o pojedinom prediktoru.

Tablica 6. Beta koeficijenti regresijskih modela

\begin{tabular}{|c|c|c|c|}
\hline \multirow[b]{2}{*}{ Prediktori } & \multicolumn{3}{|c|}{ Zavisne varijable } \\
\hline & Iskazivanje emocija & Tituliranje & $\begin{array}{c}\text { Neverbalna } \\
\text { komunikacija }\end{array}$ \\
\hline Dob & 0,029 & $0,380^{*}$ & $-0,045$ \\
\hline Radna pozicija & $-0,151$ & $-0,188$ & $-0,008$ \\
\hline Učestalost pregovaranja & $0,217^{*}$ & 0,053 & $0,220^{*}$ \\
\hline
\end{tabular}

${ }^{*} p<0,05$ 
U slučaju varijable iskazivanje emocija jedino je statistički značajna ovisnost o učestalosti pregovaranja. Tituliranje je ovisno jedino o dobi gdje je beta koeficijent najveći, a neverbalna komunikacija ovisna je o učestalosti pregovaranja. Ostale ovisnosti nisu se pokazale statistički značajnima.

\section{ZAKLJUČAK}

Brojni su činitelji koji utječu na pregovarački proces, ponašanje pregovarača za pregovaračkim stolom $\mathrm{i}$ ishode pregovaranja. Detaljno poznavanje faza pregovaračkog procesa, taktika i strategija i činitelja koji utječu na cjelokupni proces pregovaranja pomaže pregovaračima ostvariti učinkovitu interakciju sa suprotnom pregovaračkom stranom i postizanje željenih ciljeva pregovaranja. S tim u vezi, razumijevanje kulturoloških sličnosti i razlika od iznimne je važnosti za pregovarače u suvremenom globaliziranom okruženju.

Različite dimenzije kulture utječu na rezultate pregovora, a kulturološka osviještenost pregovarača pridonosi cjelovitom razumijevanju ponašanja suprotne pregovaračke strane, njezinih interesa, preferencija, taktika i strategija te osigurava određenu prednost pregovaraču za pregovaračkim stolom. $U$ radu se razmatrao utjecaj odabranih obilježja hrvatskih pregovarača (dob, pozicija u poduzeću i učestalost pregovaranja) na kulturološke aspekte pregovaranja (tituliranje, neverbalnu komunikaciju i iskazivanje emocija). Rezultati istraživanja ukazali su na postojanje pozitivne korelacije između varijabli učestalost pregovaranja i iskazivanje emocija, dob i tituliranje te učestalost pregovaranja i neverbalna komunikacija. Nadalje, beta koeficijenti regresijskih modela ukazali su na statistički značajnu ovisnost iskazivanja emocija i neverbalne komunikacije o prediktoru učestalost pregovaranja te ovisnost tituliranja o prediktoru dobi.

Ograničenja provedenog istraživanja odnose se na ograničen broj varijabli obuhvaćenih istraživanjem što ostavlja prostor za buduća istraživanja. Varijable kao što su tržišni položaj, vlasništvo ili geografski položaj poduzeća u ovom slučaju nisu uzeti u obzir. Osim navedenih, buduća istraživanja trebaju uzeti u razmatranje dodatna obilježja pregovarača, npr. spol, razinu obrazovanja, komunikacijski stil i sklonost preuzimanju rizika. Vezano uz varijablu dobi koja je istražena, buduća istraživanja bi mogla promatrati i testirati razlike u pregovaračkom kontekstu između pripadnika različitih generacijskih skupina (Baby Boomers, generacija $\mathrm{X}$, generacija $\mathrm{Y}$ i sl.).

Također, u budućim se istraživanjima potrebno usredotočiti na dodatna pregovaračka obilježja koja mogu uključivati asertivnost, kulturološku osviještenost, povjerenje, fleksibilnost i kreativnost. S obzirom na ograničenu literaturu koja obrađuje pregovaračka obilježja hrvatskih menadžera, ovo istraživanje daje uvid u određene kulturološke aspekte poslovnog pregovaranja hrvatskih menadžera i može služiti kao temelj za provođenje budućih istraživanja u hrvatskom pregovaračkom kontekstu.

\section{LITERATURA}

Acuff, F. L. (2008) How to negotiate anything with anyone anywhere around the world, New York: Amacom

Age, L. J., Eklinder-Frick, J. (2017) "Goal-oriented balancing: happy-happy negotiations beyond win-win situations", Journal of Business \& Industrial Marketing, 32(4), p. 525-534 
Barry, B., Fulmer, I. S., Goates, N. (2006) "Bargaining with Feeling: Emotionality in and Around Negotiation". In: Negotiation Theory and Research, Thompson, L. L. (Ed.), New York: Taylor and Francis, p. 99-128

Blume, A. W. (2017) Social Issues in Living Color: Challenges and Solutions from the Perspective of Ethnic Minority Psychology, Santa Barbara: Praeger

Brett J., Thompson L. (2016) “Negotiation”, Organizational Behavior and Human Decision Processes, 136, p. 68-79

Brett, J. M. (2017) “Culture and negotiation strategy”, Journal of Business \& Industrial Marketing, 32(4), p. 587-590

Brett, J., Mitchell, T. (2019) "Searching for trustworthiness: culture, trust and negotiating new business relationships", International Journal of Conflict Management, https://www.emerald.com/insight/content/doi/10.1108/ IJCMA-05-2019-0085/full/html (Accessed 9 September 2019)

Butt, A. N., Choi, J. N. (2010) "Does power matter?: Negotiator status as a moderator of the relationship between negotiator emotion and behaviour", International Journal of Conflict Management, 21(2), p. 124-146

Calero, H. H. (2005) The Power of Nonverbal Communication: How You Act is More Important Than what You Say, Aberdeen: Silver Lake Publishing

Carnevale, P. J. (2019) "Strategic time in negotiation", Current Opinion in Psychology, 26, p. 106-112

Carrell, M. R., Heavrin, C. (2004) The Everyday Negotiator: 50 Practical Negotiation Tactics for Work and Life, Amherst: HRD Press

Dabić, M., Podrug, N., Tipurić, D. (2015) “Cultural Differences Affecting Decision-Making Style: A Comparative Study Between 4 Countries", Journal of Business Economics and Management, 16(2), p. 275 -289

Dwyer, J., Hopwood, N. (2019) The Business Communication Handbook, South Melbourne: Cengage

ElShenawy, E. (2010) “Does negotiation training improve negotiators' performance?", Journal of European Industrial Training, 34(3), p. 192-210

Frascogna, X. M., Hetherington, H. L. (2001) The Lawyer's Guide to Negotiation: A Strategic Approach to Better Contracts and Settlements, Chicago: American Bar Association

Gates, S. (2012) The Negotiation Book: Your Definitive Guide To Successful Negotiating, West Sussex: John Wiley \& Sons

Gunia, B. C., Brett, J. M., Gelfand, M. J. (2016) “The science of culture and negotiation”, Current Opinion in Psychology, 8, p. $78-83$

Hair, J. F., Hult, G. T. M., Ringle, C. M., Sarstedt, M. (2016) A primer on partial least squares structural equation modeling (PLS-SEM), Thousand Oaks: Sage Publications

Hendon, D. W., Hendon, R. A., Herbig, P. (1996) Cross-cultural Business Negotiations, Westport: Quorum Books

Hoechlin, N. (2018) How to Negotiate Anything: The best negotiation book on training essentials, skills, techniques \& style: Yes, become a business negotiation genius via this in-depth book on the art of negotiation, JNR Publishing Book

Hurn, B., Tomalin, B. (2013) Cross-Cultural Communication: Theory and Practice, Hampshire: Palgrave Macmillan

Jäger, A., Loschelder, D. D., Friese, M. (2015) “How self-regulation helps to master negotiation challenges: An overview, integration, and outlook", European Review of Social Psychology, 26(1), p. 203-246

Katz, L. (2006) Negotiating International Business: The negotiator's reference guide to 50 countries around the world, Charleston: Booksurge Publishing

Katz, L. (2008) Principles of Negotiating International Business: Success Strategies for Global Negotiators, Charleston: Booksurge Publishing

Khan, M. A., Ebner, N. (2019) The Palgrave Handbook of Cross-Cultural Business Negotiation, Verlag: Springer International Publishing

Kopelman, S., Rosette, A.S., Thompson, L. (2006) "The three faces of Eve: Strategic displays of positive, negative, and neutral emotions in negotiations", Organizational Behavior and Human Decision Processes, 99(1), p. 81-101 
Kopelman, S., Rosette, A.S. (2008) "Cultural variation in response to strategic emotions in negotiations", Group Decision and Negotiation, 17, p. 65-77

Korobkin, R. (2014) Negotiation: Theory and Strategy, New York: Wolters Kluwer Law \& Business

Križman Pavlović, D., Kalanj, I. (2008) "Uloga poslovnog pregovaranja u stjecanju konkurentske prednosti", Ekonomska istraživanja, 21(4), p. 62-81

Lažnjak, J. (2011) "Dimensions of National Innovation Culture in Croatia: Content Validity of Hofstede's Dimensions", Društvena istraživanja, 20(4), p. 1015-1038

Lempereur, A. (2012) "Responsible negotiation: exploring the forest beyond the tree", Journal of Global Responsibility, 3(2), p. 198-207

Lewthwaite J. (2006) Managing People for the First Time: Gaining Commitment and Improving Performance, London: Thorogood Publishing

Olekalns, M., Weingart, L. R. (2008) “Emergent Negotiations: Stability and Shifts in Negotiation Dynamics”, Negotiation and Conflict Management Research, 1(2), p. 135-160

Oliver, D. (2011) How to Negotiate Effectively, London: Kogan Page

Perkov D., Primorac D., Kozina G. (2016) "Business negotiation as a crucial component of sales". In: Proceedings of the 13th International Scientific Conference on Economic and Social Development, Barcelona: Varaždin Development and Entrepreneurship Agency and University North, p. 638-647

Pinkley R. L, Northcraft, G. B. (2014) Get Paid What You're Worth: The Expert Negotiators' Guide to Salary and Compensation, New York: St. Martin's Press

Podrug, N., Gauta, N. (2013) “Komparativna analiza stilova upravljanja konfliktima između Hrvatske i SAD-a", Ekonomski pregled, 64(2), p. 123-142

Podrug, N., Filipović, D., Stančić, I. (2014) "Analysis of cultural differences between Croatia, Brazil, Germany and Serbia", Ekonomska istraživanja, 27(1), p. 818-829

Posthuma, R. A. (2012) "Conflict management and emotions", International Journal of Conflict Management, 23(1), p. 4-5.

Rajh, E., Budak, J., Anić, I.-D. (2016) “Hofstede's culture value survey in Croatia: Examining regional differences", Društvena istraživanja, 25(3), p. 309-327

Salacuse, J. W. (1998) “Ten Ways that Culture Affects Negotiating Style: Some Survey Results", Negotiation Journal, 14(3), p. $221-240$

Saorin-Iborra, C. M., Redondo-Cano, A., Revuelto-Taboada, L. (2013) How BATNAs perception impacts JVs negotiations, Management Decision, 51(2), p. 419-433

Sobral, F., Carvalhal, E., Almeida, F. (2008) "The Influence of Culture on Negotiation Styles of Brazilian Executives", Management Research, 6(2), p. 107-119

Thomas, D. C. (2008) Cross-Cultural Management: Essential Concepts, London: Sage Publications

Tomašević Lišanin, M. (2004) "Pregovaranje - poslovni proces koji dodaje vrijednost", Zbornik Ekonomskog fakulteta u Zagrebu, 2(1), p. 143-158

Tomašević Lišanin M., Razum A., Marić N. (2015) "Skills and negotiation behaviour of Croatian Businessmen", International Journal of Sales, Retailing and Marketing, 4(4), p. 168-178

Tomašević Lišanin, M., Kadić-Maglajlić, S., Drašković, N. (2019) Principi prodaje i pregovaranja, Zagreb: Sveučilište u Zagrebu, Ekonomski fakultet

Tracy, J. L., Randles, D., Steckler, C. M. (2015) "The nonverbal communication of emotions", Current Opinion in Behavioral Sciences, 3, p. 25-30

Uher T. E., Loosemore M. (2004) Essentials of Construction Project Management, Sydney: UNSW Press 
M. Martinović, K. Vojvodić, A. Pušić: Kulturološki aspekti poslovnog pregovaranja menadžera hrvatskih... Zbornik Veleučilišta u Rijeci, Vol. 8 (2020), No. 1, pp. 103-119

Wang, H. K. H. (2018) Business Negotiations in China: Strategy, Planning and Management, New York: Routledge

Wang M., Han Y., Su Y. (2017) "Social contagion or strategic choice?: The interpersonal effects of emotions during Chinese negotiations", Chinese Management Studies, 11(3), p. 463-478

Warner, C. (2011) Media Selling: Television, Print, Internet, Radio, Chichester: Wiley-Blackwell 


\title{
CULTURAL ASPECTS OF CROATIAN MANAGERS' BUSINESS NEGOTITATION
}

\author{
Marija Martinović \\ PhD, Associate Professor, University of Dubrovnik, Department of Economics and Business Economics, \\ Lapadska obala 7, 20000 Dubrovnik, Croatia; e-mail: marija.martinovic@unidu.hr
}

\section{Katija Vojvodić}

PhD, Associate Professor, University of Dubrovnik, Department of Economics and Business Economics, Lapadska obala 7, 20000 Dubrovnik, Croatia; e-mail: katija.vojvodic@unidu.hr

\section{Ana Pusić}

M. A., Teaching Assistant, University of Dubrovnik, Department of Economics and Business Economics, Lapadska obala 7, 20000 Dubrovnik, Croatia; e-mail: apusic@unidu.hr

\begin{abstract}
In the context of negotiation, it is of the utmost importance to understand the differences across cultures and their impact on the negotiation process and its outcomes. Furthermore, cultural awareness allows negotiators to anticipate and interpret their counterpart's behaviour. Consequently, it facilitates achieving the desired negotiating objectives and enhances negotiation performance. The aim of this paper was to explore the impact of the selected features of Croatian negotiators (age, hierarchical level and negotiation frequency) on cultural aspects of negotiation (use of titles, nonverbal communication and expression of emotion). The research was conducted on a sample of 256 firms in the Republic of Croatia. The research results revealed a positive correlation between the following variables: expression of emotion and negotiation frequency, age and the use of titles and negotiation frequency and nonverbal communication. Multilinear hierarchical regression provided a more detailed insight into the correlation between variables. Beta coefficient showed a statistically significant dependence of variables expression of emotion and nonverbal communication on the predictor negotiation frequency; as well as the dependence of the variable use of titles on the predictor age. The paper provides insights into the Croatian negotiation practice and it could serve as a basis for conducting future empirical research in the field.
\end{abstract}

Key words: business negotiation, Croatian managers, cultural aspects 